\title{
UM ESTUDO SOBRE A SATISFAÇÃO DO CONSUMIDOR ESPORTIVO QUE FREQUENTA ESTÁDIOS DE FUTEBOL EM BELO HORIZONTE
}

\section{1- André Francisco Alcântara Fagundes*}

Doutor em Administração pela Universidade Federal de Minas Gerais (UFMG), Brasil.

Professor da Faculdade de Gestão e Negócios (FAGEN) da Universidade Federal de Uberlândia (UFU), Brasil. andrefagundes@fagen.ufu.br

http://lattes.cnpq.br/4605993276758331

\section{2- Ricardo Teixeira Veiga}

Doutor em Administração pela Universidade Federal de Minas Gerais (UFMG), Brasil.

Professor do Centro de Pós-Graduação em Administração da Universidade Federal de Minas Gerais (UFMG), Brasil. ricardo.necc@gmail.com

http://lattes.cnpq.br/2160652000585374

\section{3- Danilo de Oliveira Sampaio}

Doutor em Administração pela Universidade Federal de Minas Gerais (UFMG), Brasil.

Professor da Faculdade de Administração e Ciências Contábeis da Universidade Federal de Juiz de Fora (UFJF), Brasil. danilo.sampaio@ufjf.edu.br

http://lattes.cnpq.br/0823851256773575

\section{4- Caissa Veloso e Sousa}

Doutora em Administração pela Universidade Federal de Minas Gerais (UFMG), Brasil.

Professora da Faculdade Novos Horizontes (FNH), Brasil.

caissaveloso@yahoo.com.br

http://lattes.cnpq.br/6713072836977893

\section{5- Élcio Eduardo de Paula Santana}

Doutor em Administração pela Universidade Federal do Paraná (UFPR), Brasil.

Professor da Faculdade de Gestão e Negócios (FAGEN) da Universidade Federal de Uberlândia (UFU), Brasil. santana@fagen.ufu.br

http://lattes.cnpq.br/7567021432621129

\section{6- José Edson Lara}

Doutorado em Economia de I'Empresa pela Universitat Autònoma de Barcelona, Espanha.

Professor da Fundação Pedro Leopoldo (FPL), Brasil.

jedson2010@hotmail.com

http://lattes.cnpq.br/8334601935016625

\author{
Diego Maganhotto Coraiola - Editor Geral \\ Editor responsável pela submissão: \\ Salomão Alencar de Farias. \\ Artigo analisado via processo de revisão duplo cego (Double-blind). \\ Recebido em: 19/06/2012 \\ Aprovado em: 09/01/2013 \\ última Alteração: 29/11/2012
}

\footnotetext{
* Contato Principal: Av. João Naves de Ávila, 2121. Campus Santa Mônica Bloco F - sala 1F216. Uberlândia-MG, Brasil. CEP: 38408-144.
} 
UM ESTUDO SOBRE A SATISFAÇÃO DO CONSUMIDOR ESPORTIVO QUE FREQUENTA ESTÁDIOS DE FUTEBOL EM BELO HORIZONTE

\section{RESUMO}

O esporte tem-se posicionado como importante indústria da economia mundial. Acredita-se que a promoção de relevantes eventos esportivos que estão agendados para acontecer no Brasil, como a Copa do Mundo de Futebol de 2014, possibilitarão um desenvolvimento mais significativo dessa indústria. Considerando essa realidade, esta pesquisa tem como objetivo entender os motivos que levam os consumidores a frequentarem estádios de futebol, elencando fatores que possam contribuir para sua maior satisfação. Para a coleta de dados foram realizados três grupos focais na cidade de Belo Horizonte-MG. Como resultado, constatou-se que os principais motivos que influenciam os torcedores a frequentarem os estádios são: time de preferência; importância da partida; encontros sociais; acessibilidade ao ingresso; e garantia de segurança. Ademais, foi possível identificar fatores que contribuem com a satisfação: resultado da partida ser favorável ao time de preferência; eventos de entretenimento; serviços de melhor qualidade; transporte rápido e seguro; e conforto do estádio.

\section{Palavras-chave}

Consumidor esportivo; Estádios de futebol; Marketing esportivo; Comportamento do consumidor; Futebol.

\section{A STUDY ABOUT THE SATISFACTION OF SPORTS CONSUMER THAT FREQUENTS FOOTBALL STADIUMS IN BELO HORIZONTE}

\section{ABSTRACT}

The sport has been positioned as an important industry in the world economy. It is believed that the promotion of relevant sporting events that are scheduled to happen in Brazil, like the FIFA World Cup 2014, will provide a most significant development of this sector. Considering this fact, this research aims to understand the reasons that lead consumers to attend football stadiums, listing factors that may contribute to their greater satisfaction. For data collection three focus groups were held in Belo Horizonte-MG. As a result, it was found that the main reasons that lead the fans to attend the stadiums are: team preference; the importance of the match; social gatherings; accessibility to the tickets, and security assurance. Furthermore, it was possible to identify factors that contribute to satisfaction: outcome of the match be favorable to team preference; entertainment events; better services, fast and safe transport, and comfort of the stadium.

\section{Keywords}

Sports consumer; Football stadiums; Sports marketing; Consumer behavior; Football. 


\section{Introdução}

O desenvolvimento do esporte como importante indústria da economia mundial é uma realidade. Em termos mundiais, o setor deve crescer $37 \%$ até 2013 , obtendo uma receita estimada em 141 bilhões de dólares. Quando se considera outros setores que mantém relação direta com o esporte - viagens, publicidade, equipamentos, vestuário, calçados, apostas, produtos licenciados e serviços profissionais esse valor aumenta substancialmente, sendo que somente em 2001 foram movimentados 370 bilhões de dólares. Apenas no Brasil, estima-se que a indústria do esporte crescerá a uma taxa anual de $6,8 \%$ até o ano de 2014. Atualmente o setor movimenta 3\% do PIB nacional, empregando mais de 300 mil pessoas (A.T Kearney, 2003; Trevisan, 2010).

Esse desenvolvimento ocorre concomitante à profissionalização do setor, tendo nesse aspecto como principais precursores os Estados Unidos e a Europa. No primeiro, têm-se como expoentes dessa evolução as quatro ligas profissionais dos esportes mais populares no país: basquete, beisebol, futebol americano e hóquei no gelo. Já na Europa, o principal exemplo de sucesso e desenvolvimento da indústria esportiva está relacionado ao futebol, cuja liga intercontinental, além das ligas de países como Inglaterra, Espanha e Itália, são responsáveis por significativa movimentação financeira. Destaca-se que apenas os 20 clubes de futebol com maior arrecadação do continente tiveram uma receita na temporada 2009/2010, segundo a Deloitte Football Money League (2011), de 4,274 bilhões de euros.

Ainda nesse preâmbulo, dois eventos esportivos quadrienais merecem destaque especial: a Copa do Mundo de Futebol, torneio que conta com 32 seleções, representando todos os continentes do planeta, organizada pela Federation Internationale de Football Association (FIFA); e os Jogos Olímpicos, organizado pelo International Olympic Comitee (IOC), que englobam uma variada gama de esportes e conta com a participação da maioria dos países do planeta - nos últimos jogos, em Pequim na China, estiveram presentes 204 países.

Esses eventos movimentam dezenas de bilhões de dólares. Somente a Copa do Mudo de Futebol da Alemanha faturou 10,5 bilhões de dólares em 2006. Já os Jogos Olímpicos de Pequim de 2008 tiveram um faturamento de 13 bilhões de dólares (Trevisan, 2010).

Apesar do esporte no Brasil ainda estar distante do nível de desenvolvimento da Europa e dos Estados Unidos, notam-se algumas mudanças positivas no setor, incluindo-se uma tímida, mas crescente, profissionalização, mesmo que em setores ou organizações específicas. Essas mudanças também estão relacionadas ao status que o país obteve nos últimos anos, principalmente devido à promoção de importantes eventos esportivos que estão agendados para acontecer no Brasil, como a Copa do Mundo de Futebol, que será realizada em 2014, e os Jogos Olímpicos do Rio de Janeiro, agendado para 2016.

A perspectiva de arrecadação com os Jogos Olímpicos do Rio de Janeiro é de 51,1 bilhões de dólares, sendo que está previsto um investimento em infraestrutura - estradas, aeroportos, telecomunicações e arenas esportivas - de 18 bilhões de dólares. Para a Copa do Mundo de Futebol em 2014 a previsão, conservadora, é que seja necessário o investimento de 10 bilhões de reais apenas nas 12 sedes do evento (Cabrini, 2009).

Para se obter sucesso nesses eventos, inclusive financeiro, torna-se necessário um planejamento e controle minucioso, incluindo nesse aspecto o marketing, que é essencial para o sucesso de qualquer evento esportivo (Pitts \& Stotlar, 2002; Pozzi, 1998).

Torna-se relevante enfatizar que uma parte significativa dos investimentos nesses eventos serão destinados às arenas esportivas, sendo que tanto para a Copa do Mundo de Futebol, quanto para os Jogos Olímpicos, serão construídos diversos novos estádios e ginásios esportivos. Destaca-se que essas arenas serão responsáveis por receber tanto os espectadores dos dois eventos quanto o público local, após o término desses torneios. Assim, o investimento em construção e reforma das praças de prática esportiva deve considerar não apenas os dois eventos, mas também o futuro uso desses locais.

Neste sentido, visando contribuir com o conhecimento nesse setor específico do marketing, essa pesquisa buscou entender os motivos que levam os torcedores a frequentarem jogos de futebol em estádios de Belo Horizonte. Também se busca elencar fatores que podem contribuir para uma maior satisfação desses consumidores esportivos. Assim, o estudo procurou responder o seguinte problema de pesquisa: quais os fatores motivacionais que influenciam a satisfação dos consumidores que frequentam estádios para assistir futebol em Belo Horizonte? 
Optou-se por analisar o consumidor esportivo devido à pequena publicação acadêmica referente ao assunto, principalmente no concernente aos estudos realizados no Brasil (Fagundes, Sampaio, Sousa \& Lara, 2010). Com isso, acredita-se que a pesquisa pode contribuir academicamente, principalmente para a área de marketing, por analisar o consumidor esportivo, considerado um dos principais autores da indústria do esporte. Ademais, também se espera contribuir para a análise e seleção das melhores estratégias para alocação dos investimentos previstos no tocante a construção das arenas esportivas para os dois importantes eventos que ocorrerão no Brasil, considerando-se, para tanto, o ponto de vista do consumidor esportivo que frequenta os estádios de futebol.

Para alcançar o objetivo do estudo, foram realizados três grupos focais com jovens universitários da cidade de Belo Horizonte-MG.

\section{Referencial Teórico}

Com o objetivo de auxiliar a tarefa de responder à questão de pesquisa apresentada, o referencial teórico deste trabalho abordará os seguintes assuntos: marketing esportivo; consumidor esportivo; e aspectos que influenciam na satisfação do consumidor esportivo.

\subsection{Marketing Esportivo}

Mullin, Hardy e Sutton (2004, p. 18), afirmam que "o marketing esportivo consiste em todas as atividades designadas a satisfazer as necessidades e desejos dos consumidores esportivos através de processos de troca". Os autores apontam a existência de dois eixos: (a) o marketing de produtos e serviços esportivos diretamente para os consumidores esportivos; e (b) o marketing de outros produtos e serviços por meio da utilização das promoções esportivas.

Considerando-se as fontes de receita no setor esportivo, Pozzi (1998) aponta como as principais: (a) receitas de bilheteria; (b) concessões e merchandising; (c) direito de imagem dos atletas; e (d) direitos de transmissão pela TV. Destaca-se que a indústria do esporte oferece para os seus consumidores tanto produtos como serviços. Todavia, o esporte apresenta alguns diferenciais em relação a outros negócios, conforme apresentado na Figura 1.

\begin{tabular}{|c|c|}
\hline Categoria & Diferenças específicas \\
\hline $\begin{array}{l}\text { mercado de } \\
\text { produtos e serviços } \\
\text { esportivos }\end{array}$ & $\begin{array}{l}\text { - As organizações esportivas, ao mesmo tempo, competem e cooperam. } \\
\text { - Os consumidores esportivos consideram-se especialistas devido à ênfase esportiva e } \\
\text { à sua identificação pessoal com o esporte. }\end{array}$ \\
\hline O produto esportivo & $\begin{array}{l}\text { - Há uma grande oscilação na demanda dos consumidores pelo esporte. } \\
\text { - É intangível, efêmero, perecível, subjetivo, inseparável e tende a ser experiencial. } \\
\text { - São produzidos e consumidos simultaneamente. } \\
\text { - São consumidos publicamente e a satisfação é afetada pelo convívio social. } \\
\text { - Não há controle sobre a composição do produto principal. } \\
\text { - Podem ser classificados como produtos tanto de consumo quanto industriais. } \\
\text { - Carrega em si um apelo universal e atinge todos os elementos da vida das pessoas. }\end{array}$ \\
\hline O custo do esporte & $\begin{array}{l}\text { - O custo dos produtos esportivos é geralmente baixo em comparação ao custo total } \\
\text { pago pelo consumidor na sua aquisição. } \\
\text { - As receitas indiretas são, com frequência, maiores que as receitas operacionais } \\
\text { diretas. }\end{array}$ \\
\hline $\begin{array}{l}\text { A promoção } \\
\text { esporte }\end{array}$ & $\begin{array}{l}\text { - Uma exposição muito grande à mídia tem resultado em uma ênfase crescente no } \\
\text { patrocínio como elemento principal do marketing esportivo. } \\
\text { - Uma boa visibilidade do esporte é atrativa para os negócios em termos de associação } \\
\text { por meio do patrocínio. } \\
\text { - A ênfase na promoção pode ser aplicada apenas às ramificações do produto, e não ao } \\
\text { produto principal. }\end{array}$ \\
\hline A dis & \\
\hline
\end{tabular}

Figura 1: Diferenciais do esporte em relação a outros negócios

Fonte: adaptado de Masteralexis, L. P., Barr, C. A., \& Hums, M. A. (1998). Principles and Practice of Sport Management. Gaithersburg-Maryland: An Aspen Publication; e de Morgan, M., \& Summers, J. (2008). Marketing Esportivo. São Paulo: Thomson Learning. 
Pode-se dividir as atividades e processos dos serviços oferecidos aos consumidores de eventos esportivos em três partes: (i) "parte da frente"; (ii) "parte de trás"; e (iii) "circunstancial" (Tomlinson et al., 1995 como citado em Trein \& Barcellos, 2006). No primeiro caso, estão classificados os fatores que influenciam os consumidores no momento em que os serviços são prestados: disponibilidade e acesso a alimentos; limpeza e organização da arena; atmosfera do evento; conforto das cadeiras; entre outros. Na "parte de trás" estão os fatores que antecedem o evento em si, porém influenciam diretamente a experiência vivida pelo espectador: acesso à arena; preços e acesso aos ingressos; estacionamento; horário do evento; meios de transporte disponíveis; entre outros. Já os fatores "circunstanciais" envolvem os que são incontroláveis, mas influenciam a frequência dos consumidores nos eventos: posição na tabela do time para o qual o consumidor torce; qualidade técnica das equipes; e outros.

Considerando essa divisão de atividades e processos dos serviços ofertados aos consumidores em eventos esportivos, torna-se importante destacar as relações entre os agentes interessados nesse processo, que são citados por Teitelbaum e Luce (1995) como: o investidor e/ou patrocinador; o esporte e seus atores; e o consumidor de esporte, sendo que ambos interagem entre si. Os autores afirmam que esses agentes mantêm uma relação de interdependência, demonstrando assim a importância de cada um para o sucesso de ambos.

Para Pozzi (1998) é primordial que as organizações esportivas desenvolvam estratégias voltadas para conquistar mais espectadores, pois isso tende a aumentar os valores das fontes de receita do setor. Pitts e Stotlar (2002) e Morgan e Summers (2008) corroboram com esse pensamento, sendo que os autores ainda destacam que no atual nível de crescimento do setor, a tendência é que a concorrência aumente, o que gera a necessidade de implementação de estratégias inovadoras para atrair, satisfazer e conquistar a lealdade dos consumidores do setor esportivo.

\subsection{Consumidor Esportivo}

Pitts e Stotlar (2002) destacam que o consumidor esportivo pode ser alocado em três tipos de segmentos: (i) prática esportiva - que é oferecida ao consumidor como produto de participação e/ou entretenimento; (ii) produtos esportivos - produtos e serviços, como equipamentos esportivos e serviços médicos, ofertados aos consumidores para a prática de esportes; e (iii) promoção esportiva - produtos e serviços que são ofertados para promover o esporte, incluindo eventos, brindes e patrocínios, por exemplo. Para cada um desses segmentos o consumidor esportivo apresenta motivadores distintos, o que tende a não ocorrer na maioria dos produtos ou serviços ofertados por outros setores.

Os autores apontam o vasto conjunto de produtos oferecidos na indústria do esporte, o que confirma o elevado nível de complexidade envolvido nas escolhas dos seus consumidores. Nesse sentido, Mullin et al. (2004) destacam que o consumidor esportivo apresenta-se mais suscetível às influências tanto ambientais como individuais. A Figura 2 apresenta um esboço das influências no comportamento desse tipo de consumidor.

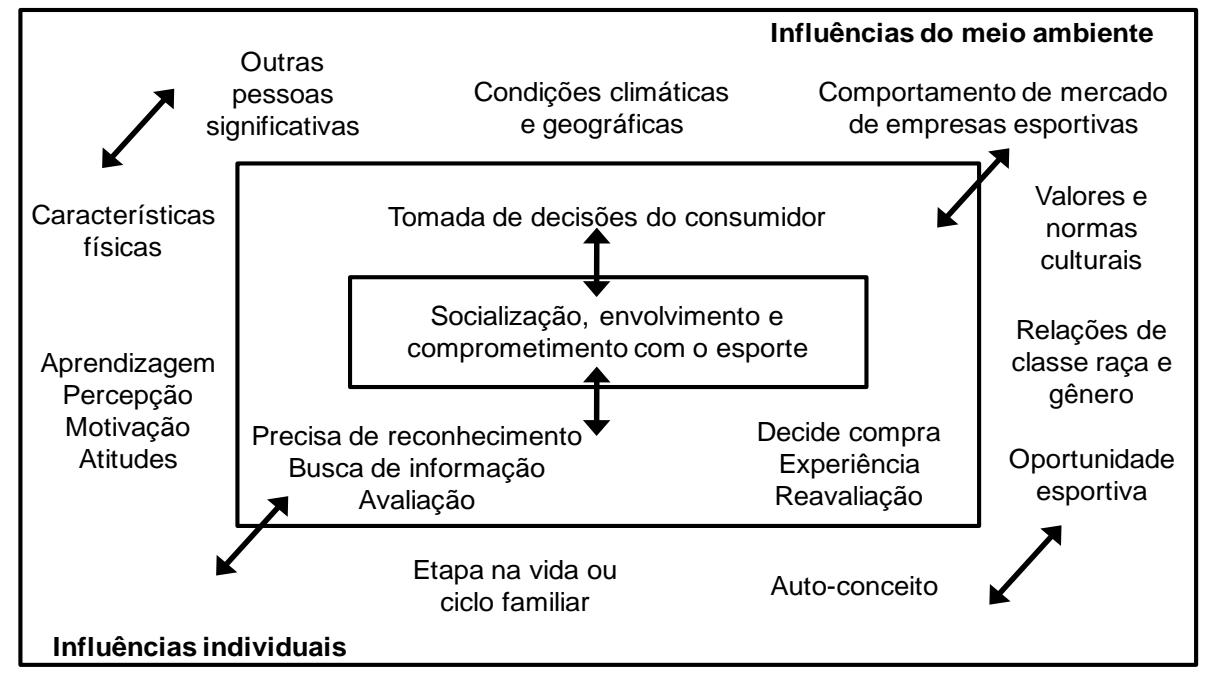

Figura 2: Influências no comportamento do consumidor esportivo

Fonte: Mullin, B. J., Hardy, S., \& Sutton, W. A. (2004). Marketing Esportivo (2a ed., p. 53). Porto Alegre: Bookman/Artemd. 
Rein, Kotler e Shields (2008) consideram que a crescente concorrência e esportes novos ou emergentes cooperam para fragmentar o mercado esportivo, dificultando a atuação das organizações do setor. Os autores atribuem as seguintes características a esse mercado dinâmico: (a) ambiente altamente competitivo; (b) torcedores com expectativas elevadas; (c) conflito entre o conceito de esporte como negócio e como competição; (d) surgimento de novas tecnologias; (e) interesses cada vez mais individuais dos consumidores; (f) mudanças na estrutura e no comportamento das famílias; e (g) falta de tempo dos consumidores.

Os autores ainda tratam dos conectores fundamentais, que são dois pontos de contato que conectam os torcedores ao esporte. O primeiro é o "astro", que pode envolver um jogador, equipe, torneio, estádio ou outro elemento que atraia torcedores. A outra conexão é estabelecida pelo "local", que se relaciona com a necessidade de interação comunitária e de filiação dos torcedores. Também existem os conectores de comunicação social, cujos elementos de conexão são: a "moeda social", que trata o esporte como uma forma das pessoas compartilharem informações, incentivando a interação social; e a "família", devido ao fato do esporte, no ambiente familiar, poder ser considerado um fator de união. O último grupo de conectores são os de busca, compostos por três formas de conexão: "experiências indiretas"; "incerteza", que considera a imprevisibilidade do esporte; e "utopia", que considera as experiências esportivas que representam o passado do torcedor.

Os autores também apontam os seguintes canais de acesso para os torcedores: (a) prática esportiva; (b) experiência no local; (c) mídia; (d) divulgação boca a boca; e (e) mentor - indivíduo interessado em envolver outras pessoas no esporte. Tanto os conectores como os canais de acesso podem influenciar o nível de envolvimento dos torcedores, que é apresentado na Figura 3.

\begin{tabular}{|l|l|}
\hline Fanáticos & $\begin{array}{l}\text { Os mais persistentes e participantes, tendem a se identificar totalmente com o esporte, } \\
\text { rara-mente faltam com seu apoio à equipe preferida, tanto pessoalmente como } \\
\text { financeiramente }\end{array}$ \\
\hline Conhecedores & $\begin{array}{l}\text { Fãs que têm amplo acesso e intensa participação nos meandros do mundo dos eventos } \\
\text { esportivos }\end{array}$ \\
\hline Agregados & $\begin{array}{l}\text { Torcedores que querem estar sempre junto das equipes e dos seus heróis e ter } \\
\text { oportunidades continuadas de trocar saudações com eles, ou concretizar outra } \\
\text { experiência de interação }\end{array}$ \\
\hline Colecionadores & $\begin{array}{l}\text { Fãs sempre dispostos a pagar bem por produtos que de alguma forma simbolizem o } \\
\text { esporte preferido }\end{array}$ \\
\hline Gastadores & Pessoas dispostas a investir grande soma pelo prazer do esporte \\
\hline Curiosos & $\begin{array}{l}\text { Normalmente se relacionam com o esporte por meio da mídia, inclusive para acompanhá- } \\
\text { lo, sendo que raramente comparecem a algum evento esportivo }\end{array}$ \\
\hline Indiferentes & Pessoas que não tem interesse em esporte \\
\hline
\end{tabular}

Figura 3: Escada do Envolvimento dos Torcedores

Fonte: adaptado de Rein, I., Kotler, P., \& Shields, B. (2008). Marketing Esportivo: a reinvenção do esporte na busca de torcedores (p. 94). Porto Alegre: Bookman.

Nesse contexto, Morgan e Summers (2008, p. 131) afirmam que "os consumidores esportivos podem ser pesquisados, segmentados, perfilados e definidos como alvo, mas a essência do que querem pode ser um mistério! Isso ocorre porque o que desejam é a imprevisibilidade. Eles querem competição!" Essa característica transforma o entendimento do comportamento do consumidor esportivo em um grande desafio para os profissionais de marketing.

\subsection{Aspectos que Influenciam a Satisfação do Consumidor Esportivo}

Para Oliver (1997, p. 13) “satisfação é a resposta ao contentamento do consumidor. É o julgamento de que uma característica do produto ou serviço, ou o produto ou serviço em si, ofereceu (ou está oferecendo) um nível prazeroso de contentamento relativo ao consumo, incluindo níveis maiores ou menores de contentamento".

Considerando-se a indústria do esporte, Theodorakis, Kambitsis and Koustelios (2001) apontam cinco dimensões para mensurar a percepção de qualidade de espectadores de esportes profissionais: acesso, confiança, receptividade, tangibilidade e segurança. 
Para os autores, os profissionais de marketing devem estabelecer foco especial na qualidade dos serviços de extensão ofertados aos espectadores. A diferença da atuação desses profissionais em relação aos de outras áreas deve-se ao fato que no esporte não se pode ter controle sobre o resultado do produto principal, que é o resultado da partida disputada. Assim, é possível influenciar apenas os aspectos do serviço que são considerados extensões do produto, ou seja, os que são independentes do desempenho esportivo em si.

Dessa forma, Van Leeuwen, Quick and Daniel (2002) consideram que é essencial distinguir as duas dimensões de serviços que o espectador está exposto em eventos esportivos: (a) serviço principal, que é o jogo/partida/evento em si; e (b) serviços periféricos ou estendidos, que englobam todos os serviços não relacionados diretamente ao jogo/partida/evento - serviços de alimentação, estacionamento, entretenimento nos intervalos, e outros.

Nesse sentido, a pesquisa de Beccarini and Ferrand (2006), que investigaram os fatores que influenciam a satisfação dos consumidores que adquirem ingressos para toda a temporada da equipe francesa de futebol Olympique de Lyon, concluiu que a imagem do clube é determinante para a avaliação da satisfação. O estudo também apresentou outros elementos motivacionais para os torcedores frequentarem os jogos do time: desempenho da equipe, vontade de se expressar, prazer de ver o espetáculo e interesse pelo esporte.

Ainda considerando-se a satisfação do consumidor esportivo, tem-se a Rede de Atitude do Torcedor (FAN, do inglês fan attitude network), proposta por Funk and James (2004), que propõe um processo por meio do qual a satisfação das necessidades disponíveis serve como um catalisador para a identificação com um esporte ou equipe. Essa identificação implicará na atitude em relação à equipe ou esporte, que, por sua vez, pode influenciar no estabelecimento da lealdade do torcedor, o que implicaria na sua frequência às arenas esportivas para acompanhar a equipe ou esporte predileto.

Heere and James (2007) concluíram em seus estudos que torcedores esportivos se consideram parte de uma organização, e não meros consumidores de um produto ou serviço. Assim, para se conseguir uma maior fidelidade do torcedor em relação à sua equipe predileta, deve-se investir na identificação desses indivíduos com a equipe. Para tanto, deve-se considerar o simbolismo dessa identidade. Dessa forma, os autores propõem uma visão alternativa do torcedor, na qual a identificação com um time também é influenciada pela identidade do grupo ao qual esse indivíduo pertence.

Nesse preâmbulo, torna-se importante também considerar o Modelo do Escopo Esportivo, elaborado por Wakefield and Sloan (1995), que propõe a utilização de fatores relacionados ao estádio, resposta do espectador e fatores de moderação para se estudar a frequência dos torcedores nas arenas esportivas. Os autores concluíram que os efeitos da lealdade à equipe, estacionamento do estádio, limpeza do estádio, percepção de aglomeração e serviços de alimentação, aliados à experiência vivenciada na arena esportiva, afetam o desejo dos espectadores em continuar a frequentar o local.

Dando continuidade ao estudo anterior, Wakefield, Blodgett and Sloan (1996) consideraram que o ambiente físico do estádio poderia representar um efeito significativo na medida em que influencia a decisão dos espectadores em desejar permanecer e retornar ao estádio. Os autores concluíram que características como: acesso ao estádio; conforto dos assentos; layout do estádio; localização da arena; entre outros, impactam diretamente na sensação de prazer do torcedor, que gera uma resposta afetiva influenciadora da resposta comportamental de voltar ou não a ter a mesma experiência.

Por fim, Madrigal (1995) destaca que a satisfação dos torcedores está relacionada à experiência obtida no evento em si, incluindo o resultado. O autor sugere que a satisfação é essencial para reter o consumidor, e que ela possibilita o boca-a-boca positivo sobre o evento.

\section{Procedimentos Metodológicos}

Para o desenvolvimento desse estudo optou-se por uma pesquisa do tipo qualitativa. Ademais, ela pode ser caracterizada como descritiva, segundo Gil (2002, p. 44) esse tipo de pesquisa "têm como objetivo primordial a descrição das características de determinada população ou fenômeno ou o estabelecimento de relações entre variáveis." 
Para a coleta de dados foram realizados três grupos focais com 27 jovens entre 19 e 25 anos da cidade de Belo Horizonte-MG. Todos os participantes da pesquisa estavam cursando o ensino superior e declararam frequentar rotineiramente (duas vezes ou mais por mês) eventos esportivos.

A escolha dos participantes buscou atender a necessidade de segmentá-los em categorias semelhantes (Barbour, 2009; Godoi; Bandeira-de-Mello; Silva, 2006). Neste caso considerou-se o nível de frequência dos participantes em comparecerem a eventos esportivos, além de características socioeconômicas semelhantes.

Dessa forma, a principal distinção entre os participantes dos grupos focais relaciona-se ao gênero, uma vez que todos eles afirmaram frequentar estádios de futebol, possuem nível de instrução e idade semelhantes. A Figura 4 apresenta detalhes dos grupos focais desenvolvidos.

\begin{tabular}{|c|c|c|c|c|}
\hline Grupo Focal & $\begin{array}{c}\text { Participantes do sexo } \\
\text { masculino }\end{array}$ & $\begin{array}{c}\text { Participantes do sexo } \\
\text { feminino }\end{array}$ & $\begin{array}{c}\text { Total de } \\
\text { participantes }\end{array}$ & Data de realização \\
\hline Grupo 1 & 07 & 03 & 10 & $24 / 11 / 2011$ \\
\hline Grupo 2 & 06 & 03 & 09 & $25 / 11 / 2011$ \\
\hline Grupo 3 & 06 & 02 & 08 & $26 / 11 / 2011$ \\
\hline
\end{tabular}

Figura 4. Grupos focais desenvolvidos Fonte: dados da pesquisa.

A opção pelo grupo focal deve-se ao fato que esse método tem como objetivo "obter o entendimento dos participantes sobre o tópico de interesse da pesquisa [ ...] o focus group pode ser usado para explorar novas áreas de pesquisa e examinar questões de pesquisa bem conhecidas a partir da perspectiva dos participantes" (Godoi et al., 2006, p. 328-329).

Barbour (2009), Dias (2000) e Flick (2004) consideram que o grupo de foco representa um importante método de pesquisa para marketing, por permitir uma interação entre os entrevistados, o que possibilita uma produção de dados e insights mais detalhados que dificilmente ocorreria sem esse convívio. Os autores ainda afirmam que o grupo de foco é útil para uma orientação em relação a um novo campo de pesquisa e geração de hipóteses - o que se adéqua aos objetivos da pesquisa.

O roteiro das entrevistas do grupo focal foi composto basicamente por quatro etapas:

a) Introdução: apresentação dos pesquisadores; explicação da confidencialidade e impessoalidade da pesquisa; descrição dos objetivos do estudo; definição da duração do encontro; e explicação da dinâmica a ser adotada nos grupos focais.

b) Confirmação: foi questionado se os participantes concordavam com as normas e objetivos do estudo, e se os mesmos gostariam de continuar a participar da pesquisa - todos concordaram em participar.

c) No desenvolvimento da pesquisa foram tratados os seguintes tópicos: fatores que influenciam a presença e a ausência a um evento esportivo; influência do time para o qual se torce; impacto da qualidade e importância do evento; interferência do preço do ingresso; relevância das instalações do estádio (banheiro, lojas, estacionamento, cobertura, cadeiras, outros); papel do aspecto social (amigos, familiares, e outros) na decisão de ir ao evento; impacto do conforto na satisfação; predisposição a comprar produtos no estádio; opinião sobre as arenas esportivas que frequentam; importância da sensação de segurança no hábito comparecer ao estádio; forma que os participantes costumam ir a um evento esportivo; solicitação de sugestões para facilitar a ida a uma arena esportiva; e descrição do que para os participantes é uma experiência agradável como espectadores de um evento esportivo. Todas essas características consideraram as seguintes pesquisas apresentadas no referencial teórico: Beccarini and Ferrand (2006); Funk and James (2004); Heere and James (2007); Madrigal (1995); Theodorakis et al. (2001); Van Leeuwen et al. (2002); Wakefield and Sloan (1995); e Wakefield et al. (1996).

d) Fechamento: foi questionado se os participantes desejavam acrescentar novas informações ou situações ainda não tratadas em relação ao assunto.

Para o desenvolvimento dos grupos focais - item ' $c$ ' anteriormente apresentado - primeiramente os participantes foram questionados sobre os fatores que influenciam a ida dos mesmos ao estádio, sendo essa a questão inicial dessa parte da pesquisa. Posteriormente, foram levantadas algumas questões 
referentes aos jogos em si, como: custos e facilidade para aquisição dos ingressos; relevância da importância da partida a ser assistida no campeonato ao qual ela pertence; sensação de segurança dos participantes ao frequentarem os estádios; e transporte utilizado para assistir os jogos. Em seguida, inseriu-se no debate fatores relacionados ao estádio, como: segurança, estacionamento, qualidade das instalações e conforto. Por fim, foi discutida a importância do time para o qual os participantes torcem no hábito dos mesmos irem aos estádios, e como esses entrevistados interagem com outras pessoas nesse ambiente esportivo.

Destaca-se que para a realização dos grupos focais foram utilizadas salas e equipamentos adequados para esse método, sendo que todos as discussões foram gravadas e posteriormente transcritas, conforme recomendações da metodologia (Barbour, 2009; Godoi et al., 2006).

Para a interpretação dos dados, utilizou-se a análise de conteúdo que, segundo Bardin (2008), constitui-se num conjunto de técnicas e procedimentos para descrição do conteúdo de mensagens, objetivando-se o levantamento de informações relacionadas ao significado dessas mensagens, e não apenas a sua pura descrição.

Os dados coletados nas entrevistas passaram por uma codificação, que "é o processo pelo qual os dados brutos são transformados sistematicamente e agregados em unidades, as quais permitem uma descrição exata das características pertinentes ao conteúdo" (Bardin, 2009, p. 129). Após a codificação procedeu-se a categorização dos dados, que possibilitou o agrupamento de dados com características comuns. Nesta etapa optou-se pelo critério de categorização semântico, que acabou por originar nove categorias: (a) motivos; (b) ingressos; (c) socialização; (d) amizade; (e) qualidade; (f) preço; (g) serviços; (h) transporte; e (i) satisfação.

\section{Apresentação e Análise dos Dados}

Neste tópico optou-se por analisar individualmente as nove categorias identificadas no processo de categorização dos dados.

\subsection{Motivos Para se Frequentar Estádios de Futebol}

Na análise dos dados, constatou-se que o simples fato do time de preferência dos entrevistados jogar é o principal motivo para que eles frequentem o estádio de futebol, independente do adversário. Alguns entrevistados também afirmaram que o fato de gostarem do esporte a ser praticado tem papel importante na influência de irem ou não o evento.

O que me motiva a ir no estádio de futebol é simplesmente o fato do Cruzeiro jogar, independente de qualquer outra coisa. Agora, se for outro esporte, por exemplo a seleção desse esporte, ou um jogo com o melhor atleta do mundo, eu também gostaria de ir. (Depoimento de um dos entrevistados)

Outro fator que influencia os entrevistados é a importância da partida. Caso o jogo seja importante para o campeonato, e se os torcedores acreditarem que a torcida comparecerá em grande número, eles se sentem mais motivados a participar do evento.

Ademais, foi destacado que a ida ao evento esportivo está relacionada às pessoas que os acompanham, sendo que amigos e familiares foram os grupos mais destacados como influenciadores.

\subsection{Aquisição de Ingressos}

Os entrevistados afirmaram que aceitam fazer sacrifícios para conseguir ingresso para suas partidas prediletas, tais como dormir ou permanecer em filas por longo tempo. Uma minoria chegou a afirmar que a fila pode ser um ambiente agradável, devido à possibilidade de se discutir futebol com outros torcedores, ouvir casos, analisar o time e conhecer novas pessoas.

Eu adorava ir para a fila, porque a fila é um mundo a parte. Na final da Libertadores eu cheguei as seis horas da tarde de um dia, ia começar a vender no outro dia ao meio dia, ai todo mundo ficou a noite inteira, eu acho bacana [ ...]. Fazemos amigos... (Depoimento de um dos entrevistados) 
Todavia, essa não é a opinião da maioria, que consideram a fila algo desagradável, mas o benefício de assistir a partida pessoalmente compensa o desgaste na opinião de todos participantes do grupo de foco.

Um fato destacado pelos entrevistados é o programa de relacionamento com torcedores do time de alguns deles. Esse programa possibilita ao torcedor adquirir um cartão magnético que permite a entrada nas partidas que o time disputa como mandante. Para adquirirem esse produto os torcedores fazem uma inscrição e pagam mensalmente uma taxa que é equivalente ao valor de todos os ingressos do time no período de um mês. Alguns entrevistados afirmaram que devido à filiação ao programa começaram a frequentar mais assiduamente as partidas dos seus times, uma vez que o cartão representa a facilidade de ter o ingresso sem as dificuldades de adquiri-lo nas bilheterias dos estádios e pontos de venda.

\subsection{Pré-jogo e Pós-jogo}

Uma discussão não planejada que emergiu dos grupos focais foi pertinente aos eventos anteriores e posteriores aos jogos. Os participantes afirmaram gostar da atmosfera ao redor do estádio antes dos jogos e disseram que costumam frequentar esses locais chegando com antecedência à partida. Eles aproveitam esses momentos para consumir iguarias típicas, que normalmente não adquirem em outros lugares, como o feijão tropeiro servido no estádio "Mineirão". Além disso, devido à proibição da venda de bebida alcoólica dentro dos estádios, os entrevistados afirmaram que vários torcedores comparecem com antecedência para beber nas redondezas do local da partida. Para alguns, esses momentos pré-jogo são considerados encontros sociais, ao possibilitarem uma interação com outras pessoas, conhecidas ou não.

O período posterior aos jogos também é utilizado pelos entrevistados para se confraternizarem, sendo comum participarem de festas ou irem para bares junto com os amigos torcedores. Todavia, eles afirmaram que esse hábito é comum apenas quando o desempenho do time para o qual torcem atende às suas expectativas.

Antes do jogo reúno com os amigos na porta do estádio, levo cerveja, às vezes churrasqueira. [ ...] Futebol é festa, quando você vai para um jogo você vai com expectativa do time ganhar, você pensa vou começar aqui, o Cruzeiro vai ganhar, depois vai para outro lugar comemorar, divertir pra caramba, entendeu? Vai pessoas, amigos também, é um programa legal, domingo, por exemplo, quando não tem nada para fazer, é um programa a mais para fazer. (Depoimento de um dos entrevistados)

\subsection{Amizade}

Apesar da existência de diversas interações sociais, tanto antes, como durante e após os jogos, os entrevistados afirmaram que fazem distinção entre os amigos exclusivos do estádio e os que são amigos em todas as situações. Eles explicaram que alguns amigos também são torcedores, e que nesse caso a relação de amizade tende a se fortalecer. Mas, por outro lado, para eles é raro estabelecer uma relação de amizade com algum torcedor dentro do estádio que transcenda o convívio relacionado aos provocados pelo time para o qual ambos torcem.

Como já apontado nas motivações que levam os entrevistados a frequentarem os estádios de futebol, eles reforçam a importância da existência de uma interação social, por meio da qual convivam e conversem com outras pessoas durante as partidas, sendo esse, inclusive, uma condição essencial para o comparecimento aos estádios.

\subsection{Qualidade do Evento}

Mesmo os participantes da pesquisa afirmando que para irem ao estádio é essencial que o time deles esteja jogando, eles foram unânimes em considerar que tanto a qualidade do evento, como das equipes envolvidas, influenciam no nível de esforço que estão dispostos a empreender para comparecer às partidas.

Alguns afirmaram que a presença de jogadores importantes e consagrados é um motivo que os faria assistir uma partida, mesmo que esta tenha pouca importância para o campeonato. Esse influenciador é mais presente quando se considera jogadores que eles normalmente não têm possibilidade de assistir. 
O Cruzeiro tinha acabado de perder a Libertadores, perdeu a Libertadores na quarta, aí domingo ia jogar contra o Corinthians, e desde quando o Ronaldo jogava no Cruzeiro eu não via o Ronaldo jogar, ai a gente chegou até a sair mais cedo do lugar que a gente tava para a gente ver o jogo. E foi um sacrifício, porque a gente tava morrendo de cansaço. (Depoimento de um dos entrevistados)

\subsection{Preço dos Ingressos}

Os entrevistados consideram justo o preço dos ingressos para os eventos esportivos que frequentam e afirmam que esse fator normalmente não interfere no hábito de irem ao estádio. Ao serem questionados sobre o que era um preço justo, afirmaram que considerando o prazer de participar do evento esportivo o preço era adequado, pois atende às expectativas que eles possuem referente à experiência de ir ao estádio.

Depende do jogo, se for a final da Libertadores o preço do ingresso não interfere não. Mas, todo mundo reclama do valor só que todo mundo vai. Eu não acho caro, em Minas é mais barato do que em São Paulo, jogo do Atlético é mais barato, mas, de qualquer forma, não acho caro, mesmo o serviço oferecido lá dentro sendo ruim. (Depoimento de um dos entrevistados)

Ainda nesse contexto, destaca-se o fato de um dos participantes da pesquisa ter afirmado que compra o ingresso "inteiro" para o jogo do seu time, mesmo sendo estudante e podendo pagar a metade do valor, pois assim sente-se contribuindo mais com o time que torce. Nenhum dos outros participantes afirmou ter se comportado de maneira semelhante, mas todos concordaram com a prática do entrevistado que relatou esse hábito.

\subsection{Serviços e Estrutura do Estádio de Futebol}

Apesar de serem questionados sobre banheiro, lojas, alimentação e limpeza, os participantes da pesquisa foram unânimes em afirmar que a segurança é o principal serviço que consideram ao avaliar a possibilidade de assistirem uma partida de futebol presencialmente. Para eles, a sensação de falta de segurança é o único item que os impediria de ir ao estádio. Eles consideram que após a proibição da venda de bebida alcoólica dentro dos estádios a segurança, ou pelo menos a sensação de segurança, aumentou. Por isso eles são favoráveis à medida, mesmo tendo vontade de consumir esse tipo de bebida durante os jogos.

Apesar de destacarem a segurança, os entrevistados afirmaram que se itens como banheiro, limpeza, cadeiras, entre outros, fossem melhores, eles se sentiriam mais satisfeitos. Mas, apesar disso, eles apontaram que já estão acostumados com a forma como encontram o estádio e aceitam essa realidade para assistirem o time que torcem se apresentar.

Eu penso o seguinte, eu vou no estádio para ver o jogo, no máximo, no máximo, eu vou comprar um refrigerante no bar [ ...] a única coisa que eu gosto, que se não tivesse não daria para ir no estádio é segurança, a única coisa que é imprescindível no futebol. Agora se for um outro esporte, todos os outros esportes são mais de elite do que o futebol, então aí eu já acho legal eu poder ir no estádio, ficar sentado, ter as coisas limpinhas, banheiro limpo, agora no estádio de futebol não faz diferença, já estou acostumado. Mas eles perdem uma oportunidade, porque se você trata o torcedor muito mal assim, você não quer passar muito tempo no estádio, é entrar e sair fora, se tivesse um shopping, restaurantes eu passaria mais tempo lá dentro e menos fora do estádio. Se os serviços fossem melhor eu pagaria mais, ou compraria mais lá dentro. (Depoimento de um dos entrevistados)

Questionados se pagariam mais pelo ingresso caso os serviços do estádio fossem melhorados, a maioria afirmou que sim, contudo, disseram acreditar que isso inibiria outras pessoas com menor poder aquisitivo a frequentar esse tipo de evento esportivo.

Ademais, foi apontado que museus e lojas poderiam influenciá-los a permanecer mais tempo no estádio e a adquirir produtos, desde que esses fossem relacionados à competição ou ao time para o qual torcem. Os entrevistados também afirmaram que prefeririam adquirir produtos nessas lojas caso elas fossem parceiras dos seus times, pois assim estariam ajudando a equipe.

Os entrevistados trataram de uma distinção que sentem entre o futebol e outros esportes - segundo eles, "de elite", como: natação, vôlei, tênis e basquete. Para os participantes da pesquisa, os frequentadores desses esportes são mais exigentes do que os de futebol, quando avaliam os serviços prestados nas arenas esportivas. 


\subsection{Transporte}

A maioria dos entrevistados afirmou que a forma de transporte não os influencia a ir ao jogo, mas eles gostariam de ter uma estrutura melhor, principalmente de estacionamento. Na opinião deles, o estacionamento do estádio que frequentam possui um preço baixo, mas o serviço é de qualidade inferior, principalmente ao final dos jogos, quando, devido à desorganização, demora-se entre 60 e 90 minutos para conseguirem sair do local.

Outro ponto destacado em relação ao estacionamento é a falta de proteção para o carro, sendo relatados durante os grupos de foco casos de carros danificados no interior do estacionamento sem o ressarcimento para os proprietários desses veículos dos prejuízos.

Os entrevistados ainda afirmaram que não utilizam transporte público devido, principalmente, a falta de segurança, mas também a lotação e demora. Assim, eles não consideram essa possibilidade, preferem ir de carro para o estádio, mesmo sabendo que enfrentarão congestionamento e problemas para estacionarem seus veículos. Contudo, eles afirmaram que se existisse um meio de transporte público ágil, seguro e confortável, prefeririam essa opção, sendo que para eles a melhor alternativa seria o metrô.

Eu só vou para o estádio de carro, porque não da para pegar ônibus. Até tem uma linha de ônibus que para em poucos lugares e vai direto para o estádio, mas essa é a pior, se eu fosse eu preferiria a outra de gente normal. Agora, se tivesse metrô, rápido, com segurança, para evitar brigas, eu ia preferir, porque ir de carro também é muito cansativo, porque demora achar vaga, demora para sair do estádio e não é seguro. Mas, do jeito que é hoje, é a única opção que eu uso, chego a revezar o carro com alguns amigos. (Depoimento de um dos entrevistados)

\subsection{Satisfação}

Para os participantes da pesquisa, o principal item para transformar a experiência de ir a um estádio em um momento agradável é que o time de preferência deles vença a partida. Eles consideram que conforto em um estádio de futebol seria comprar o ingresso com facilidade, ter um lugar seguro para estacionar e que esse local possibilitasse uma saída rápida após o jogo. Os entrevistados acreditam que esses itens pretendidos são básicos quando se analisa uma prestação de serviços, mas, considerando-se a realidade dos estádios brasileiros, se fossem supridos já significaria uma importante melhoria para o torcedor.

Quando questionados sobre o ambiente ideal, eles consideram que a arquibancada deveria ser mais próxima ao campo, para assistirem melhor a partida, sem divisão policial, com praça de alimentação diversificada, lojas e segurança. Como exemplo, citaram o modelo dos estádios europeus, mas não apontaram casos específicos.

Eles também consideram que promoções interativas com os torcedores poderiam influenciar na satisfação dos espectadores e no aumento do seu número. Além disso, sugeriram que o intervalo deveria ser mais atrativo, contando com atividades de entretenimento, como: sorteio de brindes, shows artísticos e promoções com o público - eles novamente consideraram o exemplo do exterior, dessa vez os Estados Unidos.

\section{Conclusão e Recomendações}

Os resultados da pesquisa sugerem que o componente afetivo aparenta ser mais importante do que o cognitivo, quando considerado o comparecimento dos torcedores nos estádios de futebol, principalmente ao se analisar que um dos principais motivos que influenciam esse comportamento refere-se aos times para o qual eles torcem. Assim, o comparecimento desses torcedores aos estádios está, aparentemente, mais relacionado à paixão pelo clube do que às características funcionais do serviço que estão adquirindo. Nesse contexto, pode-se considerar esse comportamento como um exemplo de conector fundamental "astro" (Rein et al., 2008), uma vez que o time de futebol para o qual os entrevistados torcem é o grande motivador dos mesmos frequentarem os estádios, independente da qualidade percebida dos serviços prestados.

Também se observou que esses consumidores tendem a minimizar os problemas encontrados na aquisição do serviço e durante a sua prestação. Acredita-se que esse comportamento deve-se ao fato que para esses torcedores o importante é acompanhar o time pelo qual torcem, além de se socializar nas arquibancadas e em momentos pré e pós jogo. Esse comportamento sugere uma importante descoberta da 
pesquisa: o hábito de ir ao estádio está mais relacionado, além do time de preferência do espectador, ao convívio social do que à estrutura e qualidade dos serviços prestados. Nesse caso, o convívio possibilitado pela ida ao estádio pode ser apontado como um exemplo de conector de comunicação social do tipo "moeda social", uma vez que a interação com outras pessoas é um motivador para os torcedores comparecerem aos jogos de seus times (Rein et al., 2008).

Ainda considerando-se a influência da interação social, os resultados da pesquisa sugerem uma importância significativa dos momentos pós jogo, quando os entrevistados afirmaram que aproveitam para se confraternizar em encontros com amigos e conhecidos. Esses encontros não necessariamente são em locais próximos ao estádio, e também não contam apenas com pessoas que estiveram presentes no evento, mas sempre têm como contexto a partida, seja para comemorar ou lamentar o seu resultado.

Nesse caso, torna-se importante destacar a proposta de Tomlinson et al. (1995 como citado em Trein \& Barcellos, 2006), que divide as atividades e processos dos serviços oferecidos aos consumidores em eventos esportivos em três partes - "parte da frente"; "parte de trás"; e "circunstanciais" - não contempla o momento pós jogo. Dessa forma, acredita-se que esse aspecto do evento esportivo merece uma maior investigação por parte da comunidade acadêmica que pesquisa o consumidor esportivo.

A pesquisa também identificou a precariedade dos serviços prestados nos estádios de futebol de Belo Horizonte, uma vez que benefícios considerados básicos são os almejados como melhorias desejadas pelos torcedores, como: segurança; facilidade de acesso aos ingressos; transporte eficaz; e estacionamento adequado. Além disso, quando questionados a cerca da qualidade dos serviços prestados, a maioria dos participantes da pesquisam declararam que consideram esses serviços de baixa qualidade. De acordo com os participantes dos grupos focais, esses são serviços básicos, mas não atendidos, e que se o fossem a satisfação aumentaria consideravelmente.

Nesse sentido, destaca-se que as melhorias desejadas pelos torcedores são contempladas pelas dimensões apresentadas por Theodorakis et al. (2001) para mensurar a percepção de qualidade de espectadores de esportes. Ainda tratando-se de dimensões, os torcedores pesquisados consideram o serviço principal, no caso o evento em si, mais importante do que os serviços periféricos ou estendidos, que são as duas dimensões de serviços que o espectador está exposto em eventos esportivos, segundo Van Leeuwen et al. (2002).

Por último, quando se consideram outros benefícios, como conforto, lojas e melhores serviços de alimentação, os entrevistados afirmaram que a melhoria desses aspectos influenciaria no aumento da satisfação e, possivelmente, até do consumo de produtos, mas que mesmo sem essas mudanças eles permanecerão frequentando os estádios. Ainda foi ressaltado que a satisfação está essencialmente relacionada ao resultado da partida, sendo que se o time pelo qual torcem obtiver um saldo positivo eles estarão satisfeitos. Essa realidade confirma o pensamento de Morgan e Summers (2008), que apontam a imprevisibilidade do resultado do evento esportivo como fator primordial para a definição da satisfação dos consumidores.

Assim, buscando-se responder de forma resumida os objetivos da pesquisa, têm-se como principais motivos que levam os torcedores de Belo Horizonte a frequentarem jogos de futebol em estádios: (a) assistir pessoalmente uma partida do time de preferência; (b) importância da partida, que inclui o desempenho do time de preferência no campeonato ao qual pertence o jogo; (c) encontros sociais antes, durante e após a partida; (d) grupos de pessoas afins que também comparecem ao estádio; (e) acessibilidade ao ingresso; e (f) garantia de segurança.

Ao se analisar os fatores que contribuem com uma maior satisfação desses torcedores, a pesquisa encontrou como principais: (a) o resultado da partida ser favorável ao time para o qual torcem; (b) realização de eventos de entretenimento em momentos anteriores a partida e no seu intervalo; (c) prestação de serviços de melhor qualidade dentro do estádio (alimentação, limpeza e segurança); (d) oferta de transporte rápido e seguro; (e) conforto nas instalações do estádio; e (f) estacionamento seguro e prático.

Dessa forma, considera-se que o objetivo de se realizar um estudo descritivo relativo ao comportamento dos consumidores de Belo Horizonte que frequentam estádios de futebol foi alcançado, sendo possível a identificação de categorias de análise para se aprofundar mais o estudo do tema. Todavia, torna-se relevante destacar alguns limites do estudo. Primeiro, que o método de grupo focal é sugerido para se conhecer melhor um tema, possibilitando uma análise descritiva sobre o mesmo, que é o objetivo 
desse estudo, contudo, sugere-se a partir dele aplicar outros métodos para uma melhor compreensão do comportamento dos indivíduos, incluindo metodologias quantitativas. Também acredita-se que consumidores de diferentes faixas etárias e condições sociais podem apresentar expectativas distintas sobre os serviços oferecidos em uma arena esportiva, fator não analisado nesse estudo, que contou com grupos homogêneos.

Considera-se como fatores positivos encontrados na pesquisa as contribuições para um melhor conhecimento do tema, pois foram apresentadas categorias de análise relacionadas ao consumidor esportivo brasileiro. Outro possível ponto positivo do trabalho foi considerar a abordagem de diferentes construtos, o que permitiu a interação dos estudos acadêmicos com as práticas cotidianas. Ademais, percebeu-se que diferentes elementos podem impactar no nível de satisfação dos consumidores estudados, o que possibilita ações gerenciais buscando atender melhor a esses clientes, podendo influenciar nos resultados das organizações.

Com relação às contribuições para a gestão de marketing esportivo, acredita-se que os resultados da pesquisa podem servir para os gestores analisarem pontos falhos nos estádios e nos serviços prestados para o torcedor comparecer aos jogos. Assim, os serviços e melhorias advindos dessa constatação podem influenciar no aumento na frequência dos torcedores aos estádios, possibilitando um resultado empresarial melhor para as organizações que gerenciam o negócio.

Como sugestão para futuras pesquisas, propõe-se que sejam realizados novos grupos focais em outras regiões do Brasil, com participantes de idades e classes sociais distintas. Outra possibilidade é que, considerando as categorias de análise dessa pesquisa, sejam estabelecidas hipóteses para serem testadas utilizando-se de outros métodos de coleta de dados, com o objetivo de se alcançar resultados que impliquem no conhecimento mais amplo do tema e do consumidor aqui analisados, inclusive utilizando-se de estudos quantitativos.

\section{Referências}

A.T Kearney. (2003). O jogo está começando. HSM Management, 4(7), 36-46.

Barbour, R. (2009). Grupos Focais. Porto Alegre: Artmed.

Bardin, L. (2008). Análise de conteúdo (4a ed.). Lisboa: Edições 70.

Beccarini, C., \& Ferrand, A. (2006). Factors Affecting Soccer Club Season Ticket Holders' Satisfaction: The Influence of Club Image and Fans' Motives. European Sport Management Quarterly, 6(1), 01-22.

Cabrini, G. (2009). Olimpíada no Rio exigirá investimento de ao menos US\$14,4 bi. Revista Exame, 953 , Ano 40. Recuperado em 04 novembro, 2011 de http://portalexame.abril.com.br/economia/olimpiada-rioexigira-investimento-ao-menos-us-14-4-bi-502794.html.

Deloitte Football Money League. (2011). Recuperado em 25 setembro, 2011 de http://www.deloitte.com/assets/Dcom-

UnitedKingdom/Local\%20Assets/Documents/Industries/Sports\%20Business\%20Group/UK_SBG_DFML2011.p df.

Dias, C. (2000). Grupo focal: técnica de coleta de dados em pesquisas qualitativas. Informação Sociedade, $10(2), 01-12$.

Fagundes, A. F. A., Sampaio, D. O., Sousa, C. V., \& Lara, J. E. (2010, maio). Marketing Esportivo: Um Estudo Exploratório da Publicação Acadêmica Brasileira. Anais do Encontro de Marketing da ANPAD, Florianópolis, SC, Brasil, 4.

Flick, U. (2004). Uma Introdução à Pesquisa Qualitativa (2a ed.). Porto Alegre: Bookman.

Funk, D C., \& James, J. D. (2004). The Fan Attitude Network (FAN) Model: Exploring Attitude Formation and Change among Sport Consumers. Sport Management Review, (7), 01-26.

Gil, A. C. (2002). Como elaborar projetos de pesquisa (4a ed.). São Paulo: Atlas.

Godoi, C. K., Bandeira-de-Mello, R., \& Silva, A. B. (Org.). (2006). Pesquisa Qualitativa Em Estudos Organizacionais: Paradigmas, Estratégias e Métodos. São Paulo: Sariva.

Heere, B., \& James, J. D. (2007). Sports Teams and Their Communities: Examining the Influence of External Group Identities on Team Identity. Journal of Sport Management, (21), 319-337.

Madrigal, R. (1995). Cognitive and Affective Determinants of Fan Satisfaction with Sporting Event Attendance. Journal of Leisure Research,27(3), 205-227. 
Masteralexis, L. P., Barr, C. A., \& Hums, M. A. (1998). Principles and Practice of Sport Management. Gaithersburg-Maryland: An Aspen Publication.

Morgan, M., \& Summers, J. (2008). Marketing Esportivo. São Paulo: Thomson Learning.

Mullin, B. J., Hardy, S., \& Sutton, W. A. (2004). Marketing Esportivo (2a ed.). Porto Alegre: Bookman/Artemd.

Oliver, R. L. (1997). Satisfaction: A Behavioral Perspective on the Consumer. Singapura: McGraw-Hill.

Pitts, B., \& Stotlar, D. (2002). Fundamentos de Marketing Esportivo. São Paulo: Phorte.

Pozzi, L. (1998). A Grande Jogada: teoria e prática do marketing esportivo. São Paulo: Globo.

Rein, I., Kotler, P., \& Shields, B. (2008). Marketing Esportivo: a reinvenção do esporte na busca de torcedores. Porto Alegre: Bookman.

Teitelbaum, I., \& Luce, F. (1995). Marketing Esportivo: uma volta de apresentação. Revista Brasileira de Administração Contemporânea, 1(5), 37-53.

Theodorakis, N., Kambitsis, C., Laios, A., \& Koustelios, A. (2001). Relationship between measures of service quality and satisfaction of spectators in Professional sports. Managing Service Quality, 11(6), 431-438.

Trein, F., \& Barcellos, P. F. P. (2006, outubro). Qualidade dos serviços em estádios de futebol. Anais do Encontro Nacional de Engenharia de Produção, Fortaleza, CE, Brasil, 26.

Trevisan, F. (2010). O mundo é uma bola. HSM Online. Recuperado em 12 janeiro, 2012, de http://br.hsmglobal.com/interior/index.php?p=imprimir_nota\&id Nota $=56167$.

Van Leeuwen, L., Quick, S., \& Daniel, K. (2002). The Sport Spectator Satisfaction Model: A Conceptual Framework for Understanding the Satisfaction of Spectators. Sport Management Review, (5), 99-128.

Wakefield, K. L., Blodgett, J. G., \& Sloan, H. J. (1996). Measurement and Management of the Sportscape. Journal of Sport Management, (10), 15-31.

Wakefield, K. L., \& Sloan, H. J. (1995). The Effects of Team Loyalty and Selected Stadium Factors on Spectator Attendance. Journal of Sport Management, (9), 153-172. 